\title{
Fine Particulate Air Pollution and Total Mortality Among Elderly Californians, 1973-2002
}

\author{
James E. Enstrom \\ Jonsson Comprehensive Cancer Center, University of California, Los Angeles, California, USA, and \\ Scientific Integrity Institute, Los Angeles, California, USA
}

\begin{abstract}
Fine particulate air pollution has been associated with increases in long-term mortality in selected cohort studies, and this association has been influential in the establishment of air quality regulations for fine particles $\left(\mathbf{P M}_{2.5}\right)$. However, this epidemiologic evidence has been questioned because of methodological issues, conflicting findings, and lack of an accepted causal mechanism. To further evaluate this association, the long-term relation between fine particulate air pollution and total mortality was examined in a cohort of $\mathbf{4 9 , 9 7 5}$ elderly Californians, with a mean age of $65 \mathrm{yr}$ as of 1973. These subjects, who resided in 25 California counties, were enrolled in 1959, recontacted in 1972, and followed from 1973 through 2002; 39,846 deaths were identified. Proportional hazards regression models were used to determine their relative risk of death (RR) and 95\% confidence interval (CI) during 1973-2002 by county of residence. The models adjusted for age, sex, cigarette smoking, race, education, marital status, body mass index, occupational exposure, exercise, and a dietary factor. For the 35,789 subjects residing in 11 of these counties, county-wide exposure to fine particles was estimated from outdoor ambient concentrations measured during 1979-1983 and RRs were calculated as a function of these $\mathrm{PM}_{2.5}$ levels (mean of $23.4 \mu \mathrm{g} / \mathrm{m}^{3}$ ). For the initial period, 1973-1982, a small positive risk was found: $R R$ was $1.04(1.01-1.07)$ for a $10-\mu \mathrm{g} / \mathrm{m}^{3}$ increase in $\mathbf{P M}_{2.5}$. For the subsequent period, 1983-2002, this risk was no longer present: RR was $1.00(0.98-1.02)$. For the entire follow-up period, RR was $1.01(0.99-1.03)$. The RRs varied somewhat among major subgroups defined by sex, age, education level, smoking status, and health status. None of the subgroups that had significantly elevated RRs during 1973-1982 had significantly elevated RRs during 1983-2002. The RRs showed no substantial variation by county of residence during any of the three follow-up periods. Subjects in the two counties with the highest $\mathbf{P M}_{2.5}$ levels (mean of $36.1 \mu \mathrm{g} / \mathrm{m}^{3}$ ) had no greater risk of death than those in the two counties with the lowest $\mathbf{P M}_{2.5}$ levels (mean of $13.1 \mu \mathrm{g} / \mathrm{m}^{3}$ ). These epidemiologic results do not support a current relationship between fine particulate pollution and total mortality in elderly Californians, but they do not rule out a small effect, particularly before 1983 .
\end{abstract}

Received 28 February 2005; accepted 21 June 2005.

The extended mortality follow-up and analyses presented in this article have been funded by the Electric Power Research Institute (EPRI). The entire funding history of CA CPS I prior to this analysis has been described elsewhere (Enstrom \& Heath, 1999; Enstrom \& Kabat, 2003). The author is responsible for all aspects of the article and declares no competing interests relevant to its contents. In the spirit of the Data Quality Act (OMB, 2003; Steinbrook, 2004), the author is willing to facilitate independent analysis of all the data used in the article. The author thanks Dr. Frederick W. Lipfert for proposing air pollution analyses with CA CPS I data and for contributing extensively to numerous versions of the text and tables, Dr. Ronald E. Wyzga for critiques of the article and for suggestions about making it as comprehensive and objective as possible, and Dr. Lingqi Tang for statistical assistance.

Address correspondence to James E. Enstrom, University of California, Jonsson Comprehensive Cancer Center, Los Angeles, CA 90095, USA. E-mail: jenstrom@ucla.edu
Many observational epidemiological studies have reported associations between air pollution from combustion sources and human health (Lipfert, 1994). During past severe air pollution events, such as the 1952 London fog incident (Logan \& Glasg, 1953), extremely high concentrations of particulate air pollution were accompanied by major increases in coincident mortality. In more recent years, health effects have also been associated with much lower concentrations of particulate air pollution (Pope \& Dockery, 1999). While much of the recent research has focused on short-term exposures, several studies suggest that long-term exposures may be more important. In particular, results from two major cohorts (Dockery et al., 1993; Pope et al., 1995, 2002) have shown significant mortality associations with outdoor concentrations of fine particles $\left(\mathrm{PM}_{2.5}\right.$, median aerodynamic diameter 
less than $2.5 \mu \mathrm{m}$ ). Other cohort studies have also examined mortality associations with $\mathrm{PM}_{2.5}$ and other pollutants (McDonnell et al., 2000; Lipfert et al., 2000, 2003), with somewhat different findings.

The major cohort studies have been used to support new national ambient air quality standards for fine particles issued by the U.S. Environmental Protection Agency (U.S. EPA, 1997). These standards are specific with respect to particle size, but not with respect to chemical composition. $\mathrm{PM}_{2.5}$ is a variable mixture, rather than a defined chemical compound as in the case of gaseous air pollutants. Fine particles are generated mainly by combustion processes and their atmospheric sequelae, and all such particles measured by the approved methods are considered equally harmful. However, the chemical composition of airborne particulate matter varies appreciably across the nation and within metropolitan areas. Although national ambient air quality standards are intended to apply throughout the nation, it is not clear that the selected epidemiological studies on which those standards are based are equally applicable nationwide.

The associations of particulate air pollution with longterm mortality remain controversial (Phalen, 2002; Moolgavkar, 2005; Kaiser, 2005). This is in large part because the epidemiologic studies that have examined these health effects are subject to a number of methodological limitations (Greenbaum et al., 2001; Moolgavkar, 1996; Gamble, 1998; Krewski et al., 2000; Lipfert, 2003). Actual exposures to air pollution are difficult to determine accurately in large cohorts. Indeed, the exposure of each individual has not been directly measured in these studies, but has been assumed to equal the ambient outdoor $\mathrm{PM}_{2.5}$ concentration for the individual's county or metropolitan area of residence. Also, one national cohort study has found largely negative associations between $\mathrm{PM}_{2.5}$ and mortality (Lipfert et al., 2000, 2003).

California is a large, diverse state that has long been concerned about the health effects of air pollution and that has recently issued new stricter ambient $\mathrm{PM}_{2.5}$ standards (CARB, 2003), based in large part on the national standards. However, no previous cohort study has focused on mortality with respect to measured $\mathrm{PM}_{2.5}$ levels in California. This article used a large cohort of elderly Californians to examine in detail the relationship between PM$_{2.5}$ levels measured during 1979-1983 and mortality from all causes during 1973-2002.

\section{METHODS}

\section{California Cancer Prevention Study}

The California Cancer Prevention Study (CA CPS I) is the extended follow-up of the 118,094 California subjects from the original Cancer Prevention Study (CPS I) of 1,078,894 adults from 25 states. CPS I was initiated by the American Cancer Society (ACS) beginning in 1959, and CA CPS I has been independently conducted at the University of California, Los Angeles (UCLA), since 1991, as described in detail elsewhere (Enstrom
\& Heath, 1999; Enstrom \& Kabat, 2003). The conduct of CA CPS I has been approved by the UCLA, Office for Protection of Research Subjects during this entire period. The subjects in this prospective cohort study were enrolled from October 1959 through February 1960 using a detailed four-page questionnaire. Surviving cohort members completed short questionnaires in late 1961, 1963, 1965, and 1972, and a two-page questionnaire in mid 1999. Deaths through 1972 were identified primarily by surviving study subjects and were confirmed with death certificates. The later deaths were identified primarily from computerized and manual matches with the California death file and the nationwide Social Security Death Index, using name and other identifying variables (Enstrom \& Heath, 1999; Enstrom \& Kabat, 2003). About $86 \%$ of the later deaths were identified on the California death file and the remainder were identified on the Social Security Death Index file. The only prior analysis of the CPS I cohort with respect to air pollution found no relationship between suspended particulate matter and lung cancer mortality during the 1960s and had no $\mathrm{PM}_{2.5}$ data (Hammond, 1972; Hammond \& Garfinkel, 1980).

This article analyzes those CA CPS I subjects who reported their cigarette smoking status in both the 1959 and 1972 questionnaires and who were alive as of January 1, 1973. Respondents to both questionnaires were traced more easily than those who responded only to the 1959 questionnaire. The 1972 questionnaire updated their cigarette smoking status, the most important confounding variable. The early years of follow-up (January 1, 1960-December 31, 1972) have not been included in this article because there are no statewide $\mathrm{PM}_{2.5}$ data before 1979 . Results for this early period and for the entire follow-up period since 1960 will be presented in a subsequent article dealing with other air pollutants. This analysis is limited to the 25 counties with the largest number of CA CPS I subjects, which ranged from 325 to 17,340 per county. About $95 \%$ of the CA CPS I subjects resided in these 25 counties. There were 49,975 traceable subjects alive as of January 1, 1973, of whom 39,846 died as of December 31,2002. There were 35,789 traceable subjects alive as of January 1, 1983 in the 11 counties with $\mathrm{PM}_{2.5}$ data, of whom 28,441 died as of December 31, 2002. An additional 2,735 subjects in these counties lost since January 1, 1973 (7.64\%), have been omitted from further analysis.

The 1999 addresses for most of the traceable subjects alive as of January 1, 1999, were determined from a match with California driver's license (DL) identifying information, and about $33 \%$ of the subjects responded to a two-page smoking and lifestyle questionnaire that was mailed in mid 1999 to their DL address (Enstrom \& Heath, 1999; Enstrom \& Kabat, 2003). Based on the questionnaire information in late 1972, the 1999 DL address information, and the death information, the county of residence and county of death were determined for most subjects as of late 1972 and early 1999. The residential mobility of subjects was assessed by calculating the percentage of subjects who lived or died in the same county from 1972 to 1999. 
1979-1983 PM$_{2.5}$ Data and 1973-2002 Mortality Data

The independent variable in this analysis is $\mathrm{PM}_{2.5}$, as measured during 1979-1983 in 11 California counties by the EPA as part of the Inhalable Particulate Network (IPN) (Hinton et al., 1984, 1986), also known as the Inhalable Particle Monitoring Network (IPMN) (Sune, 1999; Pope et al., 2002). These data have been used in several previous epidemiological studies (Ozkaynak et al., 1987; Lipfert et al., 1988, 2000, 2003; Pope et al., 1995, 2002). In this article, the $\mathrm{PM}_{2.5}$ data for each county were averaged over time and across the available monitoring stations, and are assumed to indicate the average long-term exposure level for all subjects in the county. No routinely measured $\mathrm{PM}_{2.5}$ data in California exist before 1979 or during 1984-1998; routine statewide measurements in California were resumed in 1999. The average county-level $\mathrm{PM}_{2.5}$ value was assigned to the traceable subjects alive as of January 1, 1973, based on their county of residence as of late 1972. This analysis was based on the deaths from January 1, 1973, to December 31, 2002, a 30 -year follow-up period that includes the 5-yr period of the 1979-1983 $\mathrm{PM}_{2.5}$ data. Additional analyses have been done for deaths from January 1, 1973, to December 31, 1982, and from January 1, 1983, to December 31, 2002. This latter period is roughly the same as the period (September 1, 1982-December 31,1998 ) used in the recent national cohort study (Pope et al., 2002).

\section{Analysis by Proportional Hazards Regression}

The age- and sex-adjusted relative risk of death (RR) and 95\% confidence interval (CI) were calculated using Cox proportional hazards regression, specifically the SAS PHREG procedure (SAS, 2004), including age at baseline in 1-yr intervals and sex, as a function of $\mathrm{PM}_{2.5}$ level in units of $10 \mu \mathrm{g} / \mathrm{m}^{3}$. This type of analysis is similar to the one used recently (Pope et al., 2002). Fully adjusted relative risks were calculated using a Cox model that includes age, sex, and eight potential confounding variables at baseline: cigarette smoking status (never, former as of 1959 and 1972, 1-9, 10-19, 20, 21-39, 40+ cigarettes per day as of 1972), race (white, nonwhite), education level $(<12$, $12,>12 \mathrm{yr}$ ), marital status (married, widowed, single, separated, divorced), body mass index $(<20,20-22.99,23-25.99$,

\section{TABLE 1}

Demographic and lifestyle characteristics in 1959 for California CPS I male subjects as of 1/1/1973 who resided in the 11 counties having 1979-1983 $\mathrm{PM}_{2.5}$ measurements and who provided 10/1/1972 cigarette smoking status

\begin{tabular}{|c|c|c|c|c|c|}
\hline Characteristic & $\begin{array}{c}1959 \text { value } \\
\left(11 \mathrm{PM}_{2.5}\right. \\
\text { counties })\end{array}$ & $\begin{array}{c}1959 \text { value } \\
\text { (2 highest } \mathrm{PM}_{2.5} \\
\text { counties) }\end{array}$ & $\begin{array}{c}1959 \text { value } \\
\text { (2 lowest } \mathrm{PM}_{2.5} \\
\text { counties) }\end{array}$ & $\begin{array}{l}1959 \text { value for } \\
1999 \\
\text { respondents }\end{array}$ & $\begin{array}{c}1999 \text { value for } \\
1999 \\
\text { respondents }\end{array}$ \\
\hline Mean level of $1979-1983 \mathrm{PM}_{2.5}\left(\mu \mathrm{g} / \mathrm{m}^{3}\right)$ & 23.4 & 36.1 & 13.1 & & \\
\hline Number of subjects alive as of $1 / 1 / 1973$ & 16,296 & 1043 & 1040 & & \\
\hline Lost to follow-up since $1 / 1 / 1973(\%)$ & 4.432 & 2.987 & 4.840 & & \\
\hline \multicolumn{6}{|l|}{ Number of subjects alive $1 / 1 / 1973$} \\
\hline and not lost since 1/1/1973 & 15,574 & 1012 & 990 & $\begin{array}{c}1314 \\
\text { (alive 1999) }\end{array}$ & $\begin{array}{c}1314 \\
\text { (alive 1999) }\end{array}$ \\
\hline Age as of $1 / 1 / 1973$ (mean, years) & 65.7 & 67.1 & 64.5 & 58.4 & 58.4 \\
\hline Age as of $1 / 1 / 1983$ (mean, years) & 73.8 & 74.9 & 72.4 & 68.4 & 68.4 \\
\hline Race (\% white) & 98.4 & 99.0 & 97.5 & 98.5 & 98.0 \\
\hline Marital status (\% married) & 97.3 & 97.4 & 98.0 & 96.3 & 75.6 \\
\hline Education $(\% \geq 12$ yr) & 71.8 & 70.7 & 79.8 & 90.3 & 92.6 \\
\hline Height (mean, inches) & 69.4 & 69.5 & 69.9 & 69.9 & 69.3 \\
\hline Weight (mean, pounds) & 173.0 & 172.7 & 174.5 & 172.9 & 168.9 \\
\hline History of serious diseases (\% yes) & 9.7 & 12.7 & 7.5 & 4.6 & \\
\hline Cancer & 4.6 & 6.9 & 3.8 & 3.1 & 42.5 \\
\hline Heart disease & 4.6 & 4.6 & 3.5 & 1.2 & \\
\hline Stroke & 0.6 & 1.2 & 0.2 & 0.3 & \\
\hline Sick at the present time (\% yes) & 6.8 & 6.8 & 5.4 & 6.2 & 25.9 \\
\hline Occupation (\% professional) & 10.5 & 11.9 & 9.8 & 17.5 & \\
\hline Residence location (\% urban) & 98.1 & 99.2 & 98.6 & 98.1 & \\
\hline Exercise ( $\%$ moderate or heavy) & 72.5 & 73.9 & 76.1 & 67.1 & 61.7 \\
\hline Cigarette smoking (\% current in 1959) & 41.5 & 40.5 & 45.3 & 41.9 & 1.8 \\
\hline Cigarette smoking (\% current in 1972) & 23.3 & 24.2 & 25.9 & 14.9 & 1.8 \\
\hline Fruit/fruit juices (7+ times/week) & 63.2 & 60.6 & 63.7 & 66.2 & 59.0 \\
\hline
\end{tabular}

Note. Values in 1959 and 1999 for male subjects in 11 counties who responded to 1999 questionnaire. 
TABLE 2

Demographic and lifestyle characteristics in 1959 for California CPS I female subjects as of 1/1/1973 who resided in the 11 counties having 1979-1983 PM$_{2.5}$ measurements and provided 1972 cigarette smoking status

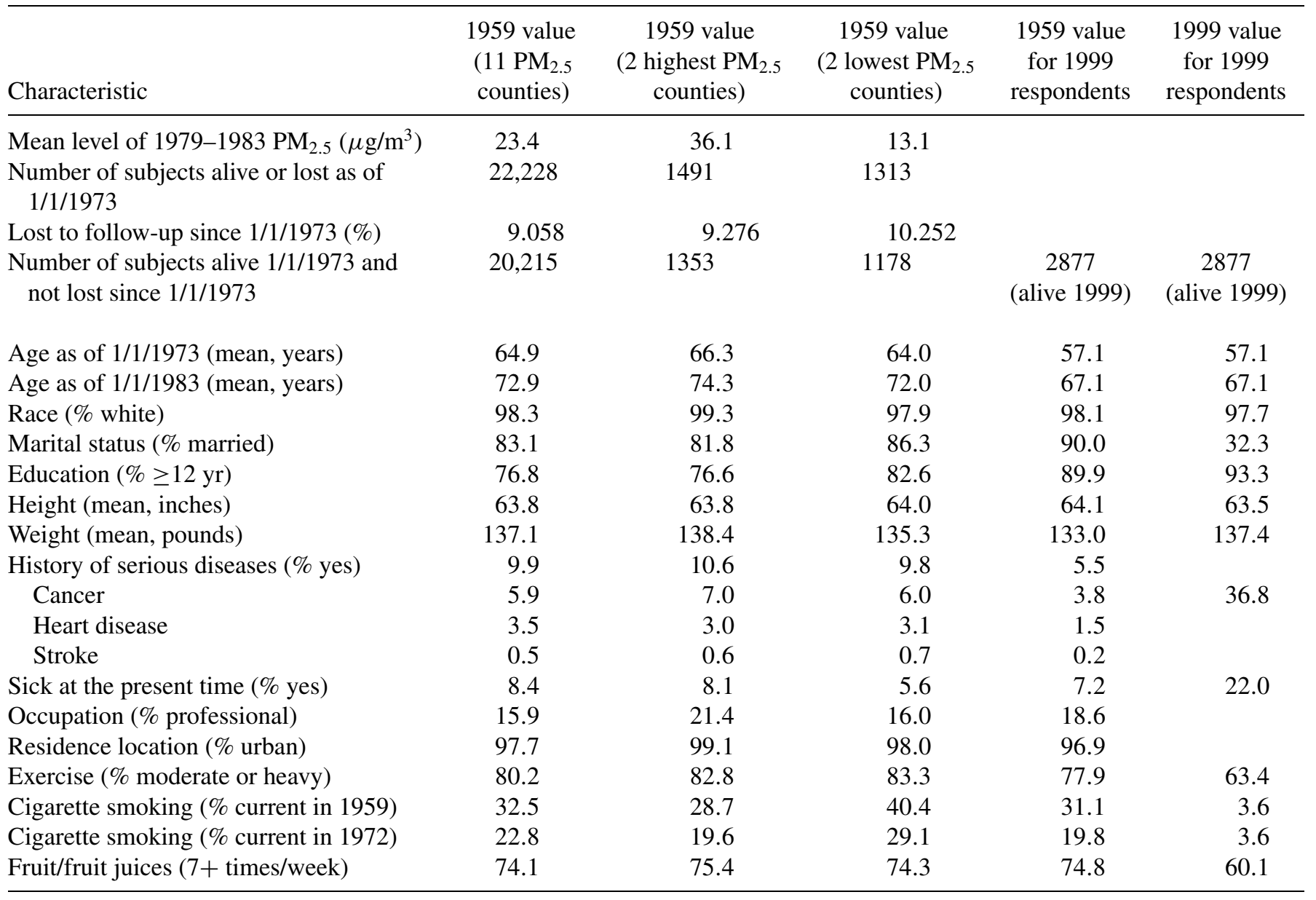

Note. Values in 1959 and 1999 for female subjects in 11 counties who responded to 1999 questionnaire.

26-29.99, >30 kg/m²), male occupational exposure (no, yes), exercise (none/slight, moderate, heavy), and fruit/fruit juice intake $(0,1,2,3,4,5,6,7$ days/wk). One additional variable, health status at entry (good, fair, poor, ill, sick/cancer/CHD/stroke), was evaluated in a sensitivity analysis. The confounding variables are defined at original entry into study in late 1959, except for cigarette smoking status, which was updated in late 1972. All of the confounding variables were measured again in a large sample of survivors during 1999.

Subgroup analyses were done by sex, year of birth (18731907, 1908-1929, representing ages 43-64 and 65-99 as of January 1, 1973), education level $(<12,12,12+\mathrm{yr})$, cigarette smoking status (never, former, current as of October 1, 1972), and health status (healthy, unhealthy as of October 1, 1959), as well as by decade of follow-up (January 1, 1973-December 31, 1982, January 1, 1983-December 31, 1992, January 1, 1993December 31,2002 ). In addition, the relative mortality rates by county of residence were calculated using PHREG as an alternative method to assess the influence of different county-wide pollution levels. The Los Angeles county subjects are used as the referent group in estimating the fully-adjusted RRs during 1973-2002, 1973-1982, and 1983-2002 for each of the other 24 counties.

\section{RESULTS}

\section{Demographic Characteristics and 1979-1983 PM $_{2.5}$ Data}

The late 1959 demographic and lifestyle characteristics of the CA CPS I subjects in the 11 counties with $1979-1983 \mathrm{PM}_{2.5}$ data (mean of $23.4 \mu \mathrm{g} / \mathrm{m}^{3}$ ) are shown in Table 1 for 15,574 males and in Table 2 for 20,218 females. These tables also show the corresponding characteristics for the subjects in the two counties (Kern and Riverside) with the highest $\mathrm{PM}_{2.5}$ levels (mean of $36.1 \mu \mathrm{g} / \mathrm{m}^{3}$ ) and in the two counties (Contra Costa and Santa Barbara) with the lowest $\mathrm{PM}_{2.5}$ levels (mean of $13.1 \mu \mathrm{g} / \mathrm{m}^{3}$ ). The characteristics of subjects are quite similar, irrespective of their mean pollution levels. The mean age of the subjects alive as of January 1, 1973, was $65.7 \mathrm{yr}$ for males and $64.9 \mathrm{yr}$ for 


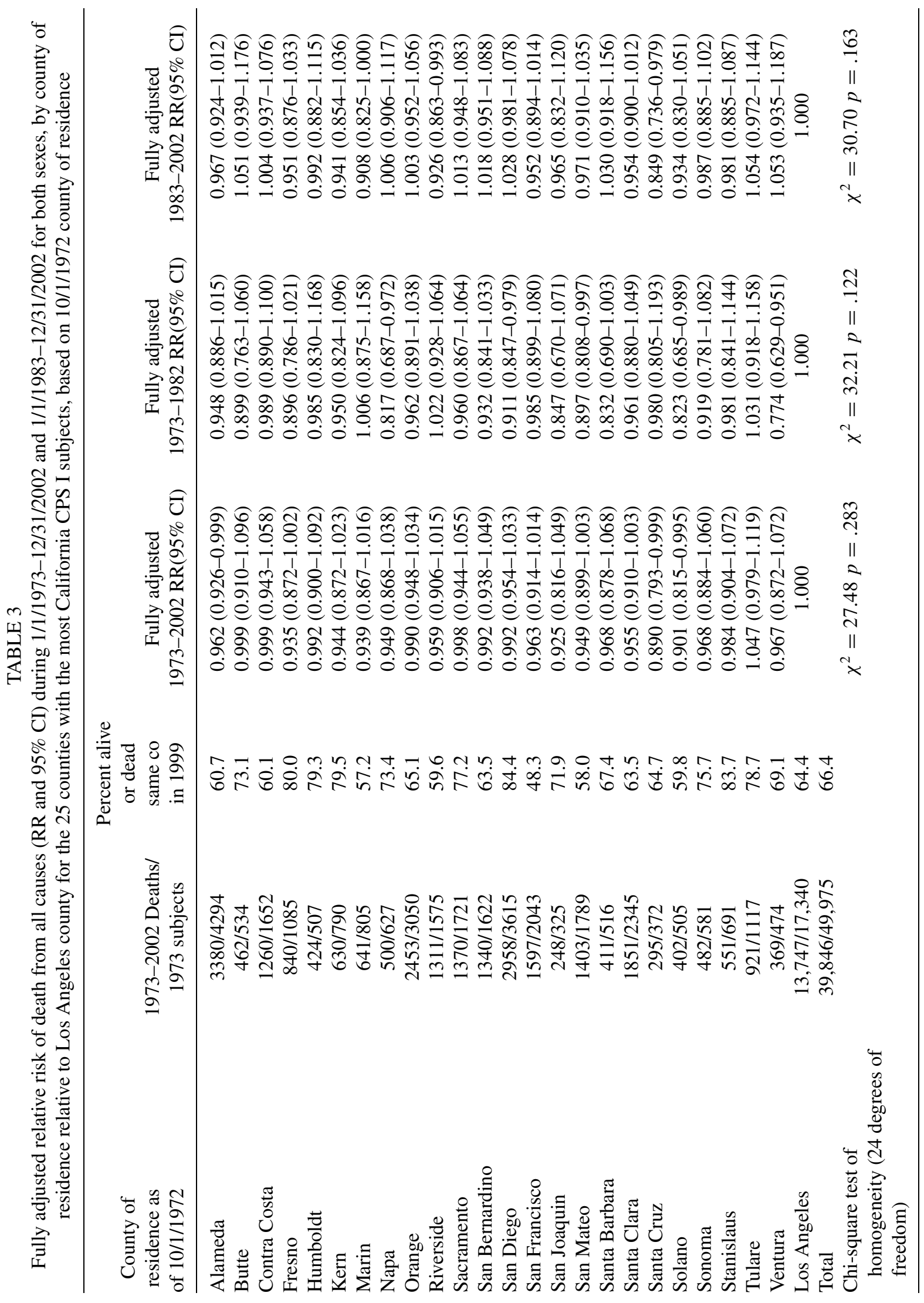




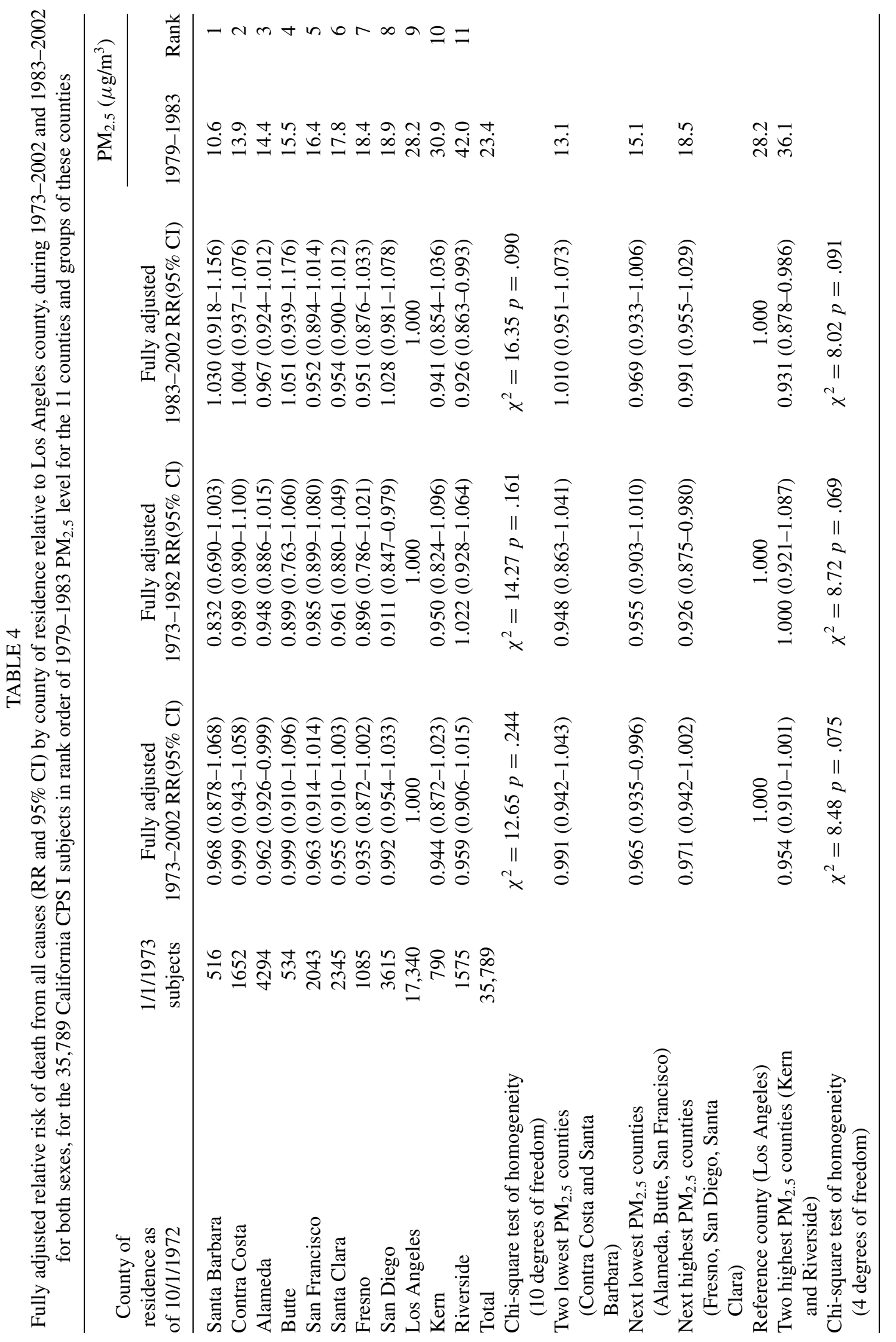


females and their minimum age was $43 \mathrm{yr}$. The mean age of the subjects alive as of January 1, 1983, was $73.8 \mathrm{yr}$ for males and $72.9 \mathrm{yr}$ for females, and their minimum age was $53 \mathrm{yr}$.

The 1979-1983 $\mathrm{PM}_{2.5}$ data from the IPN are shown in Appendix Table 1 for 11 California counties, with details for the 15 monitoring sites at which measurements were made.

The 1999 follow-up questionnaire provided important information about the confounding variables for survivors $40 \mathrm{yr}$ after they originally enrolled in the study. Although these survivors were the younger members of the cohort, with a mean age of about $57 \mathrm{yr}$ as of January 1, 1973, they provide a good indication of the risk factor changes that have occurred. A comparison of their 1959 and 1999 responses in Tables 1 and 2 shows that the variables of race, education level, exercise, body mass index, and fruit/fruit juice intake changed very little and were similar in the high and low $\mathrm{PM}_{2.5}$ counties. The percentage of married subjects declined substantially in all counties because of the large fraction of spouses who died. The percentage of current cigarette smokers declined dramatically and uniformly in all counties, reflecting the large degree of smoking cessation that has already been documented in this cohort (Enstrom \& Heath, 1999). Health status, used as an additional variable in a sensitivity analysis, also declined substantially among subjects in all counties, because the aging survivors had a much higher prevalence of cancer and other diseases in 1999 than they did in 1959.

\section{Relative Risks by County of Residence}

Table 3 shows the 1973-2002, 1973-1982, and 1983-2002 mortality risks relative to Los Angeles county, adjusted for age, sex, and eight confounding variables, for the 25 counties with the most CA CPS I subjects, including the 11 counties with 1979-1983 PM $_{2.5}$ data. Overall, the RRs were quite consistent with each other and most had a 95\% CI that included 1.0. None of the RRs were greatly different from 1.0. Wald chi-square tests conducted on these RRs did not reject the hypothesis of homogeneity during any of the three follow-up periods. Also, Table 3 shows that, based on their counties of residence and death from 1972 to 1999 , about $66 \%$ of the subjects remained in the same county during this period, indicating relative stability of residence. In particular, the stability of residence was similar in the two highest $\mathrm{PM}_{2.5}$ counties (66\%), the two lowest $\mathrm{PM}_{2.5}$ counties (62\%), and in Los Angeles county (64\%).

Table 4 shows the mortality risks relative to Los Angeles county for 11 counties ranked in order by their $1979-1983 \mathrm{PM}_{2.5}$ value. During 1973-2002, the two counties (Kern and Riverside) with highest $\mathrm{PM}_{2.5}$ levels (mean of $36.1 \mu \mathrm{g} / \mathrm{m}^{3}$ ) had an RR of 0.954 (0.910-1.001), whereas the two counties (Contra Costa and Santa Barbara) with the lowest $\mathrm{PM}_{2.5}$ levels (mean of $\left.13.1 \mu \mathrm{g} / \mathrm{m}^{3}\right)$ had a slightly higher RR of $0.991(0.942-1.043)$. During 1983-2002 there was a larger difference, with corresponding RRs of 0.931 (0.878-0.986) and 1.010 (0.951-1.073). During 1973-1982 there was a reverse pattern, with corresponding RRs of 1.000 (0.921-1.087) and 0.948 (0.863-1.041). Two groups of the six counties with medium $\mathrm{PM}_{2.5}$ levels had inter- mediate RRs that were consistent with the RRs for the high and low $\mathrm{PM}_{2.5}$ counties. Although there is some variation, Wald chisquare tests conducted on these RRs did not reject the hypothesis of homogeneity during any of the three follow-up periods for the individual counties or for the groups of counties. These findings are consistent with those in Table 3.

\section{Relative Risks by 1979-1983 $\mathbf{P M}_{2.5}$ Level}

Table 5 shows the relationship of 1973-2002 mortality to 1979-1983 $\mathrm{PM}_{2.5}$ level, by decade of follow-up, based on assigning each subject the $\mathrm{PM}_{2.5}$ level of the county in which they resided as of late 1972. Both the age- and sex-adjusted and fully adjusted 1973-2002 RRs are shown. Also shown are the 1973-2002 RRs for selected subgroups defined by sex, age (year of birth), education level, cigarette smoking status, and health status. These RRs were calculated based on a unit increase in $\mathrm{PM}_{2.5}$ of $10 \mu \mathrm{g} / \mathrm{m}^{3}$. The age- and sex-adjusted RRs and the fully adjusted RRs were slightly elevated $(\sim 1.04)$ during the first decade, 1973-1982, but were essentially 1.0 during the next two decades. Among the subgroups, the fully adjusted 1973-2002 RRs were slightly elevated (1.03) for females and younger subjects (those born during 1908-1929) and consistent with 1.0 for the others.

Table 6 shows the relationship of 1973-1982 mortality to 1979-1983 $\mathrm{PM}_{2.5}$ levels for all subjects and for the same selected subgroups. The fully adjusted RRs were significantly elevated above 1.0 for all subjects (1.04), for females (1.05), for younger subjects (1.06), for the least educated (1.07), for former smokers (1.06), and for the healthy (1.05). Table 7 shows the relationship of 1983-2002 mortality to $1979-1983$ PM$_{2.5}$ levels for all subjects and for the subgroups. Results for the entire 20 years are shown because they are virtually the same as the separate results for 1983-1992 and 1993-2002. The fully adjusted RRs were not elevated above 1.0 for any subgroup during 1983-2002. Taken as a whole, these results suggest there was a weak relationship between fine particulate pollution and mortality during 1973-1982, but none during 1983-2002. However, because of statistical fluctuation, effects of up to a $2 \%$ increase in mortality per $10 \mu \mathrm{g} / \mathrm{m}^{3}$ of $\mathrm{PM}_{2.5}$ cannot be ruled out during 1983-2002.

\section{Sensitivity Analysis of Relative Risks}

Table 8 presents a sensitivity analysis to determine the extent to which the RRs in Tables 5-7 were influenced by the confounding variables that were used. It shows the RRs during 1973-2002, 1973-1982, and 1983-2002 based on sequential proportional hazards regression models, beginning with 1979$1983 \mathrm{PM}_{2.5}$ as the only independent variable and then adding age, sex, and nine confounding variables, one at a time. The results were not particularly sensitive to the addition of any of the variables except age and cigarette smoking status. It is unknown how much the RRs would be changed if $\mathrm{PM}_{2.5}$ data were available for years before and after 1979-1983. None of the RRs during 1973-2002 and 1983-2002 were significantly elevated above 1.0 after adjustment for age, but the RRs have 
TABLE 5

Relative risk of death from all causes ( $\mathrm{RR}$ and 95\% CI) during 1/1/1973-12/31/2002 associated with change of $10 \mu \mathrm{g} / \mathrm{m}^{3}$ in 1979-1983 $\mathrm{PM}_{2.5}$, with subgroups defined by decade of follow-up, sex, year of birth, education level, cigarette smoking status as of 10/1/1972, and health status as of 10/1/1959

\begin{tabular}{lccc}
\hline & \multicolumn{3}{c}{ Model based on 1979-1983 PM $_{2.5}$} \\
\cline { 2 - 4 } Subgroups & Deaths/subjects & Age-sex-adjusted & Fully adjusted \\
RR $(95 \%$ CI $)$ & \\
\hline All subjects during each decade of full follow-up period $(1 / 1 / 1973-12 / 31 / 2002)$ & \\
$1 / 1 / 1973-12 / 31 / 1982$ & $8795 / 35,783$ & $1.032(1.003-1.062)$ & $1.039(1.010-1.069)$ \\
$1 / 1 / 1983-12 / 31 / 1992$ & $10,821 / 26,988$ & $0.989(0.964-1.015)$ & $0.996(0.970-1.022)$ \\
$1 / 1 / 1993-12 / 31 / 2002$ & $8825 / 16,167$ & $0.997(0.969-1.026)$ & $0.999(0.970-1.028)$ \\
Subjects during full follow-up period (1/1/1973-12/31/2002) & & \\
All subjects & $28,441 / 35,783$ & $1.005(0.989-1.021)$ & $1.010(0.994-1.026)$ \\
All males & $13,532 / 15,573$ & $0.996(0.973-1.020)$ & $0.993(0.970-1.016)$ \\
All females & $14,909 / 20,210$ & $1.013(0.991-1.035)$ & $1.027(1.005-1.050)$ \\
Born 1908-1929 (1973 age 43-64) & $13,354 / 20,086$ & $1.022(0.998-1.046)$ & $1.027(1.003-1.052)$ \\
Born 1873-1907 (1973 age 65-99) & $15,082 / 15,697$ & $0.991(0.970-1.013)$ & $0.996(0.975-1.018)$ \\
$<12$ yr education & $8025 / 9079$ & $1.016(0.987-1.047)$ & $1.018(0.989-1.049)$ \\
12 yr education & $6346 / 8557$ & $1.002(0.969-1.037)$ & $1.005(0.972-1.040)$ \\
$>12$ yr education & $14,070 / 18,147$ & $0.998(0.976-1.021)$ & $1.007(0.984-1.030)$ \\
Never smoker & $11,528 / 15,181$ & $1.020(0.995-1.045)$ & $1.019(0.994-1.044)$ \\
Former smoker & $10,074 / 12,400$ & $1.005(0.978-1.032)$ & $1.005(0.978-1.032)$ \\
Current smoker & $6839 / 8202$ & $1.003(0.971-1.036)$ & $0.999(0.967-1.032)$ \\
Healthy & $22,234 / 28,461$ & $1.006(0.988-1.024)$ & $1.010(0.992-1.028)$ \\
Unhealthy & $5456 / 6439$ & $0.981(0.945-1.018)$ & $0.993(0.957-1.030)$ \\
\hline
\end{tabular}

TABLE 6

Relative risk of death from all causes ( $\mathrm{RR}$ and $95 \% \mathrm{CI}$ ) during 1/1/1973-12/31/1982 associated with change of $10 \mu \mathrm{g} / \mathrm{m}^{3}$ in 1979-1983 $\mathrm{PM}_{2.5}$, with subgroups defined by sex, year of birth, education level, cigarette smoking status as of 10/1/1972, and health status as of $10 / 1 / 1959$

\begin{tabular}{lccc}
\hline & \multicolumn{3}{c}{ Model based on 1979-1983 PM PM.5 $^{2.5}$} \\
\cline { 2 - 3 } Subgroups & Age-sex-adjusted & $\begin{array}{c}\text { Fully adjusted } \\
\text { RR (95\% CI) }\end{array}$ \\
\hline Subjects during initial decade of follow-up (1/1/1973-12/31/1982) & RR (95\% CI) & \\
$\quad$ All subjects & $8795 / 35,783$ & $1.032(1.003-1.062)$ & $1.039(1.010-1.069)$ \\
All males & $4701 / 15,573$ & $1.027(0.988-1.067)$ & $1.029(0.990-1.069)$ \\
All females & $4094 / 20,210$ & $1.039(0.996-1.083)$ & $1.052(1.009-1.096)$ \\
Born 1908-1929 (1973 age 43-64) & $2637 / 20,086$ & $1.062(1.006-1.120)$ & $1.064(1.008-1.122)$ \\
Born 1873-1907 (1973 age 65-99) & $6158 / 15,697$ & $1.021(0.988-1.056)$ & $1.031(0.997-1.066)$ \\
$<12$ yr education & $3123 / 9079$ & $1.064(1.015-1.115)$ & $1.072(1.023-1.124)$ \\
12 yr education & $1686 / 8557$ & $1.045(0.980-1.115)$ & $1.046(0.981-1.116)$ \\
$>12$ yr education & $3986 / 18,147$ & $1.001(0.960-1.045)$ & $1.011(0.969-1.055)$ \\
Never smoker & $3425 / 15,181$ & $1.038(0.993-1.086)$ & $1.038(0.992-1.085)$ \\
Former smoker & $3264 / 12,400$ & $1.059(1.011-1.110)$ & $1.058(1.010-1.109)$ \\
Current smoker & $2106 / 8202$ & $1.014(0.957-1.075)$ & $1.009(0.952-1.069)$ \\
Healthy & $6432 / 28,461$ & $1.043(1.009-1.078)$ & $1.050(1.016-1.085)$ \\
Unhealthy & $2104 / 6439$ & $0.981(0.925-1.040)$ & $0.991(0.935-1.051)$ \\
\hline
\end{tabular}


TABLE 7

Relative risk of death from all causes (RR and 95\% CI) during 1/1/1983-12/31/2002 associated with change of $10 \mu \mathrm{g} / \mathrm{m}^{3}$ in 1979-1983 $\mathrm{PM}_{2.5}$, with subgroups defined by sex, year of birth, education level, cigarette smoking status as of 10/1/1972, and health status as of $10 / 1 / 1959$

\begin{tabular}{lccc}
\hline & & Model based on 1979-1983 PM 2.5 \\
\cline { 2 - 4 } Subgroups & Deaths/subjects & Age-sex-adjusted & Fully adjusted \\
RR $(95 \%$ CI $)$ & $(95 \%$ CI $)$ \\
\hline Subjects during last two decades of follow-up $(1 / 1 / 1983-12 / 31 / 2002)$ & & \\
All subjects & $19,646 / 26,988$ & $0.992(0.973-1.011)$ & $0.997(0.978-1.016)$ \\
All males & $8831 / 10,872$ & $0.979(0.951-1.008)$ & $0.974(0.947-1.003)$ \\
All females & $10,815 / 16,116$ & $1.003(0.978-1.029)$ & $1.018(0.992-1.044)$ \\
Born 1908-1929 (1983 age 53-74) & $10,717 / 17,449$ & $1.012(0.986-1.040)$ & $1.018(0.992-1.046)$ \\
Born 1873-1907 (1983 age 75-99) & $8929 / 9539$ & $0.972(0.945-0.999)$ & $0.975(0.948-1.002)$ \\
$<12$ yr education & $4902 / 5956$ & $0.987(0.950-1.025)$ & $0.986(0.949-1.024)$ \\
12 yr education & $4660 / 6871$ & $0.985(0.947-1.026)$ & $0.990(0.951-1.030)$ \\
$>12$ yr education & $10,084 / 14,161$ & $0.997(0.970-1.024)$ & $1.005(0.978-1.032)$ \\
Never smoker & $8103 / 11,756$ & $1.011(0.982-1.042)$ & $1.011(0.981-1.041)$ \\
Former smoker & $6810 / 9136$ & $0.979(0.947-1.012)$ & $0.980(0.949-1.013)$ \\
Current smoker & $4733 / 6096$ & $0.999(0.961-1.039)$ & $0.996(0.958-1.036)$ \\
Healthy & $15802 / 22,029$ & $0.990(0.969-1.012)$ & $0.994(0.973-1.015)$ \\
Unhealthy & $3352 / 4335$ & $0.980(0.935-1.028)$ & $0.995(0.949-1.043)$
\end{tabular}

upper confidence intervals as high as 1.028. All of the RRs during 1973-1982 were significantly elevated about 1.0, with upper confidence intervals as high as 1.071. Based on their large $\chi^{2}$ values, the variables of age, sex, and cigarette smoking status were by far the most important variables in the model. After inclusion of age, sex, and cigarette smoking status, the addition of the next 7 independent variables changed the RRs by only about $0.1 \%$. When initial health status was entered as an additional

TABLE 8

Relative risk of death from all causes (RR and 95\% CI) during 1/1/1973-12/31/2002, 1/1/1973-12/31/1982, and $1 / 1 / 1983-12 / 31 / 2002$ associated with change of $10 \mu \mathrm{g} / \mathrm{m}^{3}$ in $1979-1983 \mathrm{PM}_{2.5}$, by individual confounding variables defined as of 1959, except for 1972 cigarette smoking; Age, sex, and nine confounding variables are added to the proportional hazards regression model one variable at a time

\begin{tabular}{|c|c|c|c|c|}
\hline $\begin{array}{c}\text { Cumulative PHREG model } \\
\text { based on adding one } \\
\text { variable at a time }\end{array}$ & $\begin{array}{l}\text { 1973-2002 } \\
\text { Chi-square }\end{array}$ & $\begin{array}{c}1973-2002 \\
\text { RR }(95 \% \text { CI })\end{array}$ & $\begin{array}{c}1973-1982 \\
\text { RR }(95 \% \text { CI })\end{array}$ & $\begin{array}{c}1983-2002 \\
\operatorname{RR}(95 \% \mathrm{CI})\end{array}$ \\
\hline+ Age & $14,445.92$ & 1.003 (0.987-1.019) & $1.029(1.000-1.059)$ & $0.991(0.972-1.010)$ \\
\hline+ Sex & 464.16 & $1.005(0.989-1.021)^{a}$ & $1.032(1.003-1.062)^{a}$ & $0.992(0.973-1.011)^{a}$ \\
\hline +Education & 53.67 & $1.011(0.995-1.027)$ & $1.041(1.012-1.071)$ & $0.997(0.978-1.016)$ \\
\hline+ Martial status & 26.16 & $1.011(0.995-1.027)$ & $1.041(1.012-1.071)$ & $0.997(0.978-1.016)$ \\
\hline +Body mass index & 91.87 & $1.010(0.994-1.026)$ & $1.040(1.011-1.070)$ & $0.996(0.977-1.016)$ \\
\hline +Occupational exposure & 3.28 & $1.010(0.994-1.026)$ & $1.040(1.011-1.070)$ & $0.996(0.977-1.016)$ \\
\hline+ Exercise & 0.02 & $1.010(0.994-1.026)$ & 1.039 (1.010-1.069) & $0.997(0.978-1.016)$ \\
\hline
\end{tabular}

\footnotetext{
${ }^{a}$ Age-sex-adjusted RR.

${ }^{b}$ Eight-variable fully adjusted RR.
} 
TABLE 9

Fully-adjusted relative risk of death from all causes (RR and 95\% CI) by cigarette smoking status as of 10/1/1972, during 1973-2002, 1973-1982, and 1983-2002 for both sexes, for the California CPS subjects in 11 counties with 1979-1983 PM 2.5 measurements, which were used as one of the confounding variables

\begin{tabular}{lccc}
\hline \multicolumn{1}{c}{$\begin{array}{c}\text { Cigarette } \\
\text { smoking status } \\
\text { as of } 10 / 1 / 1972\end{array}$} & $\begin{array}{c}\text { Fully adjusted } \\
\text { 1973-2002 RR (95\% CI) }\end{array}$ & $\begin{array}{c}\text { Fully adjusted } \\
1973-1982 \text { RR (95\% CI) }\end{array}$ & $\begin{array}{c}\text { Fully adjusted } \\
1983-2002 \text { RR }(95 \% \text { CI })\end{array}$ \\
\hline $\begin{array}{l}\text { Deaths/subjects } \\
\text { Never (as of 1959 and 1972) }\end{array}$ & $28,447 / 35,789$ & $8801 / 35,789$ & $19,646 / 26,988$ \\
Former (as of 1959 and 1972) & 1.000 & 1.000 & 1.000 \\
Former (as of 1972 only) & $1.054(1.014-1.096)$ & $1.061(0.987-1.140)$ & $1.049(1.001-1.100)$ \\
Current: $1-9$ cpd (as of 1972) & $1.253(1.212-1.295)$ & $1.312(1.236-1.392)$ & $1.224(1.176-1.273)$ \\
Current: $10-19$ cpd (as of 1972) & $1.239(1.150-1.336)$ & $1.227(1.065-1.414)$ & $1.243(1.138-1.357)$ \\
Current: 20 cpd (as of 1972) & $1.597(1.510-1.688)$ & $1.667(1.508-1.842)$ & $1.566(1.465-1.675)$ \\
Current: $21-39$ cpd (as of 1972) & $1.871(1.791-1.953)$ & $1.829(1.689-1.980)$ & $1.887(1.792-1.987)$ \\
Current: $40+$ cpd (as of 1972) & $2.068(1.936-2.210)$ & $1.889(1.666-2.140)$ & $2.145(1.984-2.320)$ \\
Chi-square test of homogeneity (7 degrees & $2.543(2.375-2.723)$ & $2.460(2.189-2.765)$ & $2.587(2.378-2.814)$ \\
$\quad \chi^{2}=1701.75 p<.0001$ & $\chi^{2}=478.14 p<.0001$ & $\chi^{2}=1232.17 p<.0001$ \\
\hline
\end{tabular}

Note. cpd, cigarettes per day.

independent variable, the RRs decreased by $0.3 \%$. However, initial health status was not one of the eight confounding variables used in calculating the fully adjusted RRs in the other tables, because it may have been influenced by exposure to air pollution before entry into the study.

\section{Relative Risks by 1972 Cigarette Smoking Level}

Table 9 shows the fully adjusted RRs for eight levels of 1972 cigarette smoking, the strongest confounding variable in this study. Note there was a strong and clear dose-response relationship during 1973-2002. The dose-response relationship remained as strong during 1983-2002 as it was during 1973-1982, in spite of the large degree of smoking cessation that occurred from 1972 to 1999, as documented in Tables 1 and 2. This comparison supports the findings of an earlier paper, which examined smoking cessation and mortality trends in this cohort during 1960-1997 (Enstrom \& Heath, 1999). The Wald chi-square test of homogeneity for each of the three follow-up periods, where $\chi^{2}>478$ for 7 degrees of freedom, clearly rejects the hypothesis that the RRs are equal (homogeneous). The large RRs related to increasing cigarette smoking level are shown here in order to put the RRs related to increasing $\mathrm{PM}_{2.5}$ level in Table 4 in perspective.

\section{DISCUSSION}

\section{Strengths and Uncertainties of This Study}

This study has several important strengths: a large, diverse cohort of males and females distributed throughout California, a large number of deaths, extensive baseline and follow-up data on demographic and lifestyle characteristics, long-term followup of a high percentage of subjects, relative stability of sub- jects based on their residential address history, and availability of $\mathrm{PM}_{2.5}$ measurements for over $70 \%$ of the subjects. In addition, there is a wide range of $\mathrm{PM}_{2.5}$ levels (10.6 to $42.0 \mu \mathrm{g} / \mathrm{m}^{3}$ ) available for subjects in 11 counties. Although the CA CPS I cohort is not a random sample of the California population, previous examination has shown that mortality ratios based on cigarette smoking status are similar in this cohort (Enstrom \& Heath, 1999) and in a cohort representative of the US population (Enstrom, 1999).

The results of this study, as in all epidemiology studies, are dependent upon the underlying data and the analytical methods that were used. Major uncertainties include the extent to which the available air quality data represent actual exposures, the validity of the proportional hazards regression calculations of the RRs, and the potentially important confounders that may have been omitted from the analysis.

The $\mathrm{PM}_{2.5}$ air quality data are limited to 11 California counties and 8 of these counties had only one outdoor monitoring station each. The period of monitoring was from July 1979 to December 1983 and most counties had data for just a two to three year period. These sample data are assumed to represent longterm personal exposures of each subject based on their county of residence in late 1972. The validity of this assumption has not heen confirmed, but these same limited data have been used in other major cohort studies (Pope et al., 1995, 2002; Lipfert et al., 2000, 2003).

The assumption that individual exposures are the same as county-wide averages, as measured by a few centrally-located monitors, can result in the "ecological fallacy," where results based on group averages differ from those based on individual exposures (Piantadosi et al., 1988). However, it is impractical to monitor individual exposures for a large cohort, especially 


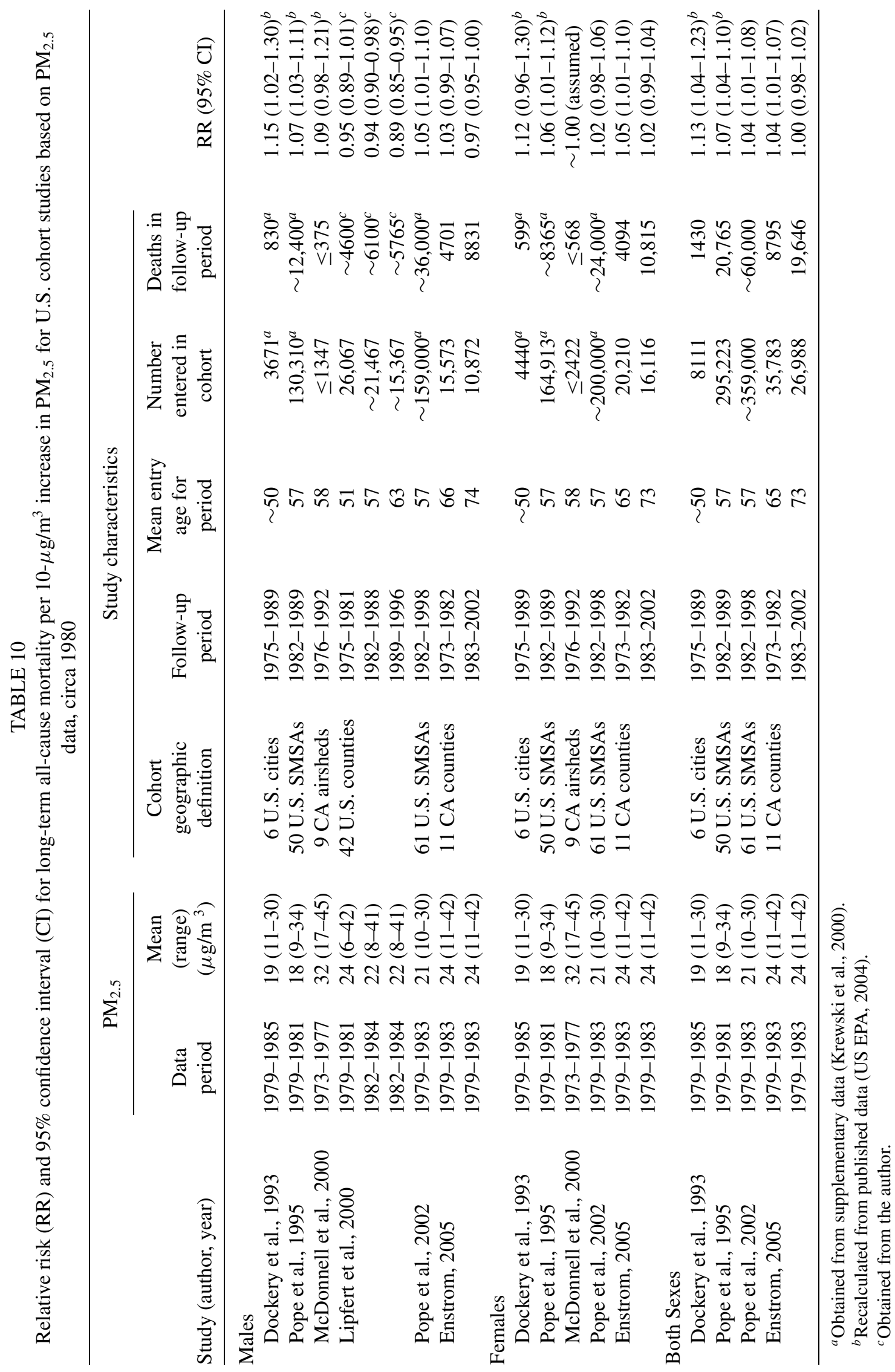


over the long-term. This analysis used the smallest practical geographic unit (counties), given typical mobility of the subjects, in hopes of minimizing exposure errors.

The relative risk results are all based on Cox proportional hazards regression (PHREG), which has been used in numerous cohort survival analyses. This statistical methodology depends on the assumption of proportionality (SAS, 2004). The validity of this assumption with respect to the $\mathrm{PM}_{2.5}$ variable has heen confirmed for most RRs in Tables 3-9 by the Kolmogorov-type supremum test of functional form (SAS, 2004). Also, previous findings on cigarette smoking and mortality in this cohort showed that relative risks based on proportional hazards regression were similar to relative risks based on life table survival analysis (Enstrom \& Heath, 1999).

With respect to the impact of additional potential confounding variables, ecological variables at the county level, such as climate, were explored and found to be uncritical. The analyses based on the eight-variable model found that after age and sex adjustment only one confounding variable, cigarette smoking status, had much impact on the RRs. Indeed, each fully-adjusted RR was within $1.5 \%$ of the corresponding age-sex-adjusted RR.

\section{Comparisons with Other Cohort Studies}

In Table 10 the major findings in this study are compared with those of the other U.S. cohort studies based on $\mathrm{PM}_{2.5}$ data, circa 1980. The basic characteristics and relative risks for all-cause mortality are given for all six studies, where each relative risk ( $R R$ and $95 \% \mathrm{CI}$ ) is based on a $10 \mu \mathrm{g} / \mathrm{m}^{3}$ increase in $\mathrm{PM}_{2.5}$. The RRs were standardized to the extent possible by using the same conversion of published results that was used by the EPA in their latest criteria document on particulate matter (US EPA, 2004). For instance, the RR of 1.07 (1.04-1.10) during 1982-1989 for both sexes in the ACS CPS II study (Pope et al., 1995) is based on a mortality difference of $17 \%$ between the highest and lowest $\mathrm{PM}_{2.5}$ areas and $\mathrm{PM}_{2.5}$ difference of $25 \mu \mathrm{g} / \mathrm{m}^{3}$. By comparison, the RR of 1.00 (0.98-1.02) during 1983-2002 among both sexes in the current CA CPS I study is based on a $\mathrm{PM}_{2.5}$ variation up to $31 \mu \mathrm{g} / \mathrm{m}^{3}$ among 11 counties.

The RRs in Table 10 range from 0.89 to 1.15 and each corresponding $95 \% \mathrm{Cl}$ either includes 1.0 or is within 0.05 of including 1.0. Thus, the relationship between $\mathrm{PM}_{2.5}$ and mortality is very weak and near the limit of detectability by epidemiologic methods. In order to define this relationship as accurately as possible, it is important to understand the differences that exist between the RRs. These differences could be due to the epidemiologic methodology used or they could be due to the characteristics of the study cohorts, such as their geographic location, follow-up period, demographics, and size. For instance, the RR of 1.07 in the ACS CPS II study is the average relationship between $\mathrm{PM}_{2.5}$ level and mortality in 50 areas of the U.S. However, detailed reanalysis of this study reveals substantial geographic variation in the relationship (Krewski et al., 2000). In particular, a map of $\mathrm{PM}_{2.5}$ levels and relative risk of mortality throughout the U.S. (Figure 21) shows that most areas of Califor- nia had medium mortality risk and no areas had high mortality risk. This pattern suggests that the relationship between $\mathrm{PM}_{2.5}$ and mortality among the California subjects in the CPS II cohort was weaker than the RR of 1.07 and consistent with the RR of 1.00 found in the CA CPS I cohort.

It is clear from Table 10 that no single result can adequately describe the relationship between $\mathrm{PM}_{2.5}$ and mortality for the entire country. The complete body of epidemiologic evidence should be used to assess this relationship as accurately as possible within the limitations of epidemiologic methodology. A full comparative examination of the available cohort studies is warranted. Ideally, a standardized method of analysis should be applied to the underlying data in each cohort and the results should be presented in a standardized way. Such an analysis would make a substantial contribution to the research priorities for particulate matter (National Research Council, 2004).

\section{REFERENCES}

California Air Resources Board. 2003. Ambient air quality standards for suspended particulate matter (PM) and sulfates. California Environmental Protection Agency, Sacramento, CA, July 5. (ftp://ftp.arb.ca.gov/carbis/regact/aaqspm/isor.pdf and www.arb.ca.gov/regact/aaqspm/aaqspm.htm).

Dockery, D. W., Pope, C. A., III, Xu, X., Spengler, J. D., Ware, J. H., Fay, M. E., Ferris, B. G., and Speizer, F. E. 1993. An association between air pollution and mortality in six U.S. cities. N. Engl. J. Med. 329:1753-1759.

Enstrom, J. E. 1999. Smoking cessation and mortality trends among two United States populations. J Clin Epidemiol 52:813.

Enstrom, J. E., and Heath, C. W., Jr. 1999. Smoking cessation and mortality trends among 118,000 Californians, 1960-97. Epidemiology 10:500-512.

Enstrom, J. E., and Kabat, G. C. 2003. Environmental tobacco smoke and tobacco related mortality in a prospective study of Californians, 1960-98. Br. Med. J. 326:1057-1061.

Gamble, J. F. 1998. $\mathrm{PM}_{2.5}$ and mortality in long-term prospective cohort studies: Cause-effect or statistical associations. Environ. Health Prospect. 106:535-549.

Greenbaum, D. S., Bachmann, J. D., Krewski, D., Samet, J. M., White, R., and Wyzga, R. E. 2001. Particulate air pollution standards and morbidity and mortality: Case study. Am. J. Epidemiol. 154:S78S90.

Hammond, E. C. 1972. Smoking habits and air pollution in relation to lung cancer. In Environmental Factors in Respiratory Disease (Edited by DH Lee). Fogerty International Center Proceedings No. 11. New York: Academic Press, 1972, Chapter 12, pages 177198.

Hammond, E. C., and Garfinkel, L. 1980. General air pollution and cancer in the United States. Prev. Med. 9:206-211.

Hinton, D. O., Sune, J. M., Suggs, J. C., and Barnard, W. F. 1984. Inhalable Particulate Network Report: Operation and Data Summary (Mass Concentrations Only). Volume I. April 1979December 1982. EPA-600/4-84-088a. Research Triangle Park, NC: U.S. Environmental Protection Agency, November 1984, particularly pages 108-113.

Hinton, D. O., Sune, J. M., Suggs, J. C., and Barnard, W. F. 1986. Inhalable Particulate Network Report: Data Summary (Mass 
Concentrations only). Volume III. January 1983-December 1984, EPA-600/4-86/019. Research Triangle Park, NC: U.S. Environmental Protection Agency, April 1986, particularly pages 53-55.

Kaiser, J. 2005. Mounting evidence indicts fine-particle pollution. Science 307:1858-1961 (http://www.sciencemag.org/cgi/reprint/307/ 5717/1858a.pdf).

Krewski, D., Burnett, R. T., Goldberg, M. S., Hoover, K., Siemiatycki, J., Abrahamowicz, M., White, W. H. and others. 2000. Reanalysis of the Harvard Six Cities Study and the American Cancer Society Study of Particulate Air Pollution and Mortality: Special report. Cambridge, MA: Health Effects Institute. Part I. Replication and Validation (http://www.healtheffects.org/Pubs/Rean-part1.pdf) and Part II. Sensitivity Analyses (http://www.healtheffects.org/Pubs/Reanpart2.pdf), particularly Figure 21 on p. 197.

Lipfert, F. W. 2003. Commentary on the HEI Reanalysis of the Harvard Six Cities Study and the American Cancer Society Study of Particulate Air Pollution and Mortality. J. Toxicol. Environ. Health A 66:1705-1714.

Lipfert, F. W. 1994. Air pollution and community health: A critical review and data sourcebook. New York: van Nostrand Reinhold.

Lipfert, F. W., Malone, R. G., Daum, M. L., Mendell, N. R., and Yang, C. C. 1988. A statistical study of the macroepidemiology of air pollution and total mortality. Brookhaven National Laboratory, Upton, NY. Report BNL 52122, April.

Lipfert, F. W., Perry, H. M., Jr., Miller, J. P., Baty, J. D., Wyzga, R. E., and Carmody, S. E. 2000. The Washington University-EPRI veterans' cohort mortality study: Preliminary results. Inhal. Toxicol. 12[S4]:41-73.

Lipfert, F. W., Perry, H. M., Jr., Miller, J. P., Baty, J. D., Wyzga, R. E., and Carmody, S. E. 2003. Air pollution, blood pressure, and their longterm associations with mortality. Inhal. Toxicol. 15(5):493-512.

Logan, W. P. D., and Glasg M. D. 1953. Mortality in London fog incident, 1952. Lancet 1:336-338.

McDonnell, W. F., Nishino-Ishikawa, N., Petersen, F. F., Chen, L. H., and Abbey, D. E. 2000. Relationship of mortality with the fine and coarse fractions of long-term ambient $\mathrm{PM}_{10}$ concentrations in nonsmokers. J. Expos. Anal. Environ. Epidemiol. 10:427-436.

Moolgavkar, S. H. 1996. A critical review of the evidence on particulate air pollution and mortality. Epidemiology 7:420-428.

National Research Council, Committee on Research Priorities for Airborne Particulate Matter 2004. Research priorities for air- borne particulate matter: IV. Continuing research progress. Washington, DC: National Academies Press. (http://www.nap.edu/ books/0309091993/html).

Office of Management and Budget. 2003. Proposed bulletin on peer review and information quality. September 15. 68FR 54023-9. (http://www.whitehouse.gov/omb/inforeg/agency_info_quality_links. html).

Ozkaynak, H., and Thurston, G. D. 1987. Associations between 1980 U.S. mortality rates and alternative measures of airborne particle concentration. Risk Analy. 7:449-461.

Phalen, R. F. 2002. The particulate air pollution controversy: A case study and lessons learned. Boston: Kluger Academic.

Piantadosi, S., Byar, D. P., and Green, S. B. 1988. The ecological fallacy. Am. J. Epidemiol. 127:893-904.

Pope, C. A. III, and Dockery, D. W. 1999. Epidemiology of particle effects. In Air pollution and health, eds. S. T. Holgate, H. Koren, R. Maynard, and J. Samet, pp. 673-705. London: Academic Press.

Pope, C. A. III, Thun, M. J., Namboodiri, M. M., Dockery, D. W., Evans, J. S., Speizer, F. E., and Heath, C. W., Jr. 1995. Particulate air pollution as a predictor of mortality in a prospective study of U.S. adults. Am. J. Respir. Crit. Care Med. 151:669-674.

Pope, C. A. III, Burnett, R. T., Thun, M. J., Calle, E. E., Krewski, D., Ito, K., and Thurston, G. D. 2002. Lung cancer, cardiopulmonary mortality, and long-term exposure to fine particulate air pollution. $J$. Am. Med. Assoc. 287:1132-1141.

SAS Institute, Inc. 2004. The PHREG Procedure. SAS/STAT 9.1 user's guide. pp. 3213-3332. (http://support.sas.com/documentation/ onlinedoc/91pdf/sasdoc_91/stat_ug_7313.pdf). Cary, NC: SAS Institute.

Steinbrook, R. 2004. Peer review and federal regulations. N. Engl. J. Med. 350:103-104.

Sune, J. 1999. Personal communication with FW Lipfert. Inhalable Particle Monitoring Network data (ipmnshrt.exe). Research Triangle Park, NC: U.S. Environmental Protection Agency.

U.S. Environmental Protection Agency. 1997. Air quality criteria for particulate matter. Fed. Reg. 62:38676.

U.S. Environmental Protection Agency. 2004. Air Quality Criteria for Particulate Matter. Volume I (EPA/600/P-99/002aF) and Volume II (EPA/600/P-99/002bF). Washington, DC, October 2004, particularly Table $8-12$ on page $8-117$ (http://cfpub.epa.gov/ncea/ cfm/partmatt.cfm). 


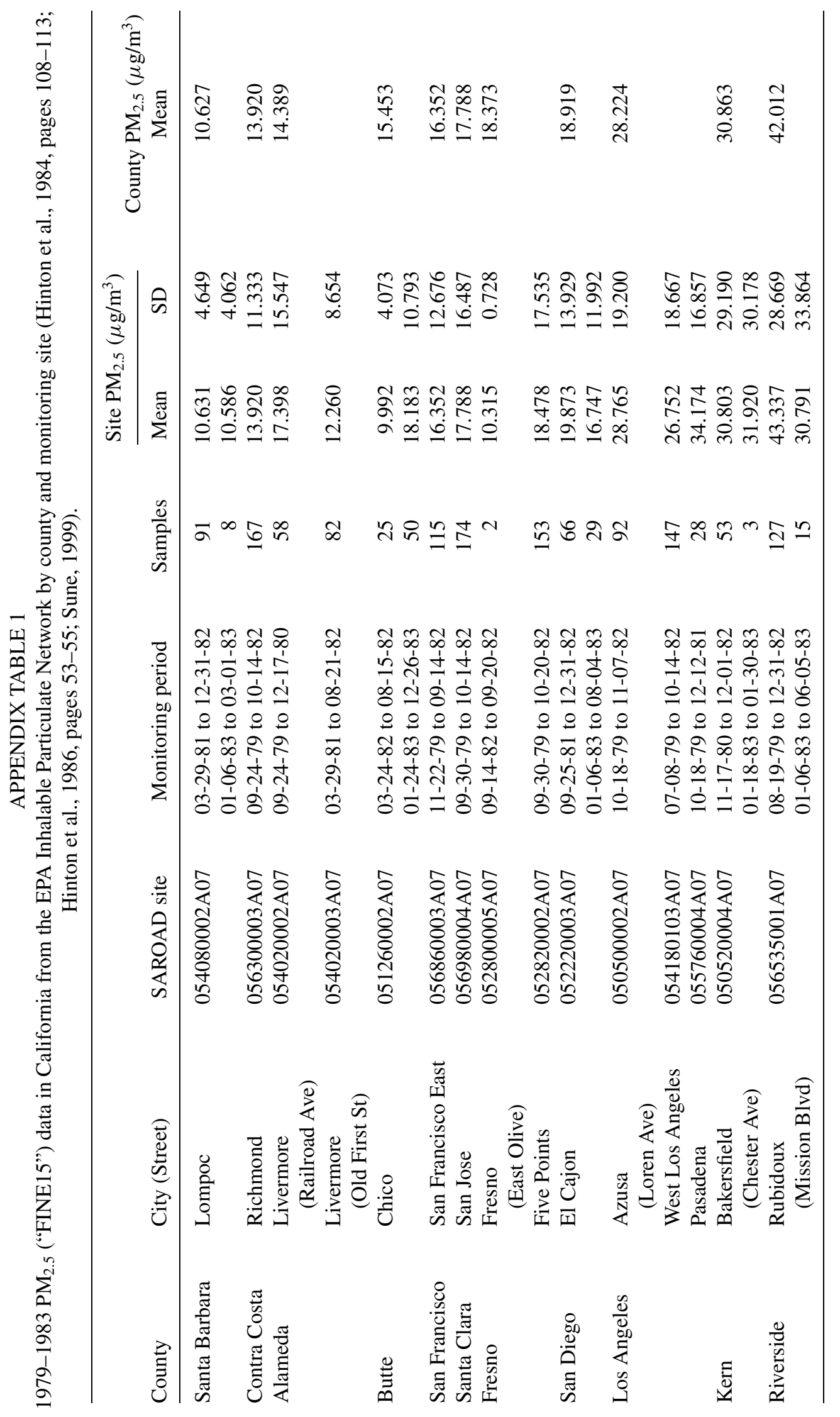

